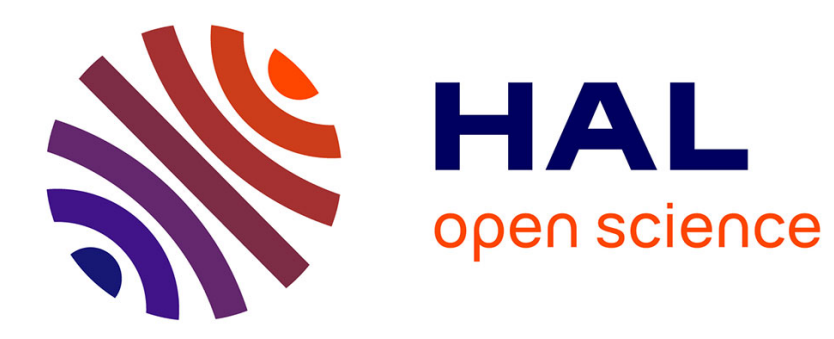

\title{
Landscape risk analysis for pesticides applied to rice paddies
}

Dimitrios G. Karpouzas, Carlo Ribarbelli, Marco Pastori, Ettore Capri

\section{To cite this version:}

Dimitrios G. Karpouzas, Carlo Ribarbelli, Marco Pastori, Ettore Capri. Landscape risk analysis for pesticides applied to rice paddies. Agronomy for Sustainable Development, 2006, 26 (3), pp.167-177. hal-00886360

\section{HAL Id: hal-00886360 https://hal.science/hal-00886360}

Submitted on 1 Jan 2006

HAL is a multi-disciplinary open access archive for the deposit and dissemination of scientific research documents, whether they are published or not. The documents may come from teaching and research institutions in France or abroad, or from public or private research centers.
L'archive ouverte pluridisciplinaire HAL, est destinée au dépôt et à la diffusion de documents scientifiques de niveau recherche, publiés ou non, émanant des établissements d'enseignement et de recherche français ou étrangers, des laboratoires publics ou privés. 


\title{
Landscape risk analysis for pesticides applied to rice paddies
}

\author{
Dimitrios G. KARPOUZAS ${ }^{a *}$, Carlo RIBARBELLI ${ }^{\mathrm{b}}$, Marco PASTORI ${ }^{\mathrm{b}}$, Ettore CAPRI $^{\mathrm{c}}$ \\ ${ }^{\text {a }}$ University of Thessaly, Department of Biochemistry - Biotechnology, Ploutonos 26 \& Aiolou, Larissa 41221, Greece \\ ${ }^{\mathrm{b}}$ Ente Regionale per I Servizi all Agricoltura e alle Foreste, ERSAF segrate, Milano, Italy \\ ${ }^{\mathrm{c}}$ Universita Cattolica del Sacro Cuore, Istituto di Chimica Agraria ed Ambientale, Sezione Chimica Vegetale, Via E. Parmense 84, Piacenza 29100, Greece
}

(Accepted 1 June 2006)

\begin{abstract}
The use of geographical information system (GIS) datasets in combination with mathematical modeling has been proven a powerful tool for modeling refinement at higher tier assessment in all crop situations. This study constitutes the first attempt to predict pesticide exposure in surface-water and groundwater systems of a rice watershed using a combination of GIS and modeling. A rice-cultivated watershed in the region of Lombardy, province of Pavia, Italy was selected. The community of Tromello is bypassed by the river Terdoppio, which along with drainage canals and streams creates a rice watershed of $467 \mathrm{ha}$, comprising 201 paddies. The watershed was conceptualized using a combination of the rice water quality (RICEWQ 1.6.4v) and river water quality (RIVWQ 2.02) models. Spatial GIS data (land use, soil properties and hydrology), on-site scouting and personal interviews with the farmers were used for modeling parameterization. Application of RICEWQ in each of the paddies provided groundwater predicted environmental concentrations for the herbicides propanil and molinate. Groundwater predicted concentrations did not exceed $0.1 \mu \mathrm{g} / \mathrm{L}$ in any of the propanil-treated paddies, unlike molinate, whose predicted concentrations exceeded $0.1 \mu \mathrm{g} / \mathrm{L}$ in 7 of the 31 molinate-treated paddies. Pesticide mass and water releases from paddies were used as inputs for canals, streams and the river, and the fate of propanil and molinate was simulated with RIVWQ. Comparison of the predicted concentrations of molinate and propanil for the year 1999 at the most downstream point of the simulated segment of the river Terdoppio, with measured values obtained from approximately the same point of the river showed a relatively good agreement. These results indicate that the combination of GIS with validated models can be a useful option for higher tier exposure assessment and modeling refinement in rice-paddy areas.
\end{abstract}

\section{GIS / landscape risk assessment / molinate / propanil / RICEWQ / RIVWQ}

\section{INTRODUCTION}

Pesticide risk assessment is mainly based on conservative approaches, which include numerous assumptions with the aim of providing a realistic worst-case scenario for the prediction of exposure (FOCUS, 2000, 2001; Med-Rice, 2003). However, in cases where a potential risk for a pesticide has been identified at tiers $1-3$, the registrants should either produce a refined modeling scheme or suggest effective mitigation measures, which should be backed up by supporting studies, thus moving to tier 4 analysis. Refined modeling is identified as a means of representing as much as possible the real agricultural situation by gradually removing conservatism included at lower risk assessment levels. A common method for establishing tier 4 analysis is to incorporate landscape spatial data from areas relevant to the uses of the pesticide examined. Such landscape information is currently provided by remote sensing and geographical information systems (GIS). Only recently, a new group, called FOCUS working group on Landscape and mitigation factors in ecological risk assessment, completed its report which included a summary of the existing tools on landscape risk analysis for pesticides and a preliminary guide on what mitigation strategies are available and how they can be implemented (FOCUS, 2006).
GIS tools can use multiple datasets such as slope, soil and hydrology parameters and land cover and analyze them in such a manner as to evaluate their co-occurrence (Kay, 1998). Integration of GIS as a pre- or post-processor of data for environmental models provides a great variety of options for higher tier risk assessment. Recently, great progress has been made in predicting spatial and temporal concentrations of pesticides at the watershed level using mathematical modeling in combination with GIS in almost all crop situations (Verro et al., 2002; Padovani et al., 2004; Cryer et al., 2006). Verro et al. (2002) developed a GIS-based system for the surface water risk assessment of the herbicide alachlor used in the corn-cultivated area of the region of Lombardy in northern Italy. Similarly, Lake et al. (2003) used GIS datasets and a relatively simple groundwater model to identify areas that are vulnerable to nitrate pollution. However, no attempts have been made so far in Europe regarding the combined use of GIS and mathematical modeling in rice-paddy watersheds. Rice is commonly cultivated under submerged conditions and local agronomic practices can exert a significant effect on water quality of rice-growing areas (Padovani et al., 2006). After reviewing most of the available monitoring data in paddy areas in Italy, Capri and Cavanna (1999) found that the concentrations of pesticides used in rice cultivation varied from $0.1-30 \mu \mathrm{g} / \mathrm{L}$ in both surface-water and groundwater systems.

* Corresponding author: dkarpouzas@ bio.uth.gr 


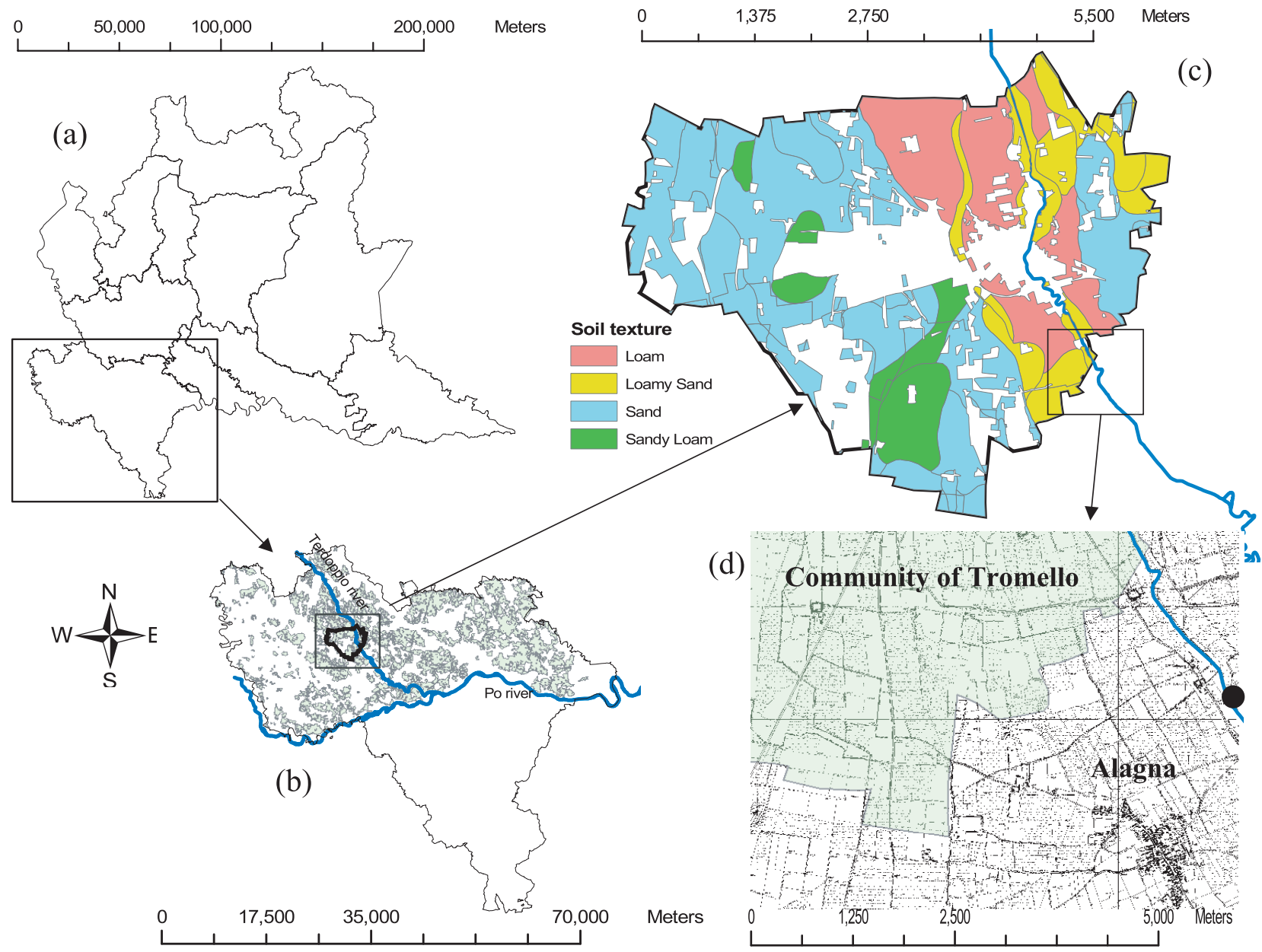

Figure 1. (a) A map of the region of Lombardy; (b) the province of Pavia with the shaded area representing the rice-cultivated land of the province and two of the main surface-water systems of the area, the rivers Terdoppio and Po, (c) the soil texture in the rice-cultivated land of the community of Tromello, and (d) the location of the sampling station in Alagna from where the samples of the monitoring study were collected (•).

Rice is commonly cultivated at river basins in southern Europe, where paddy fields, artificial and natural surface-water bodies create a unique ecosystem which should be realistically considered as a whole. Therefore, rice-cultivated basins offer an ideal example where landscape risk assessment including mathematical modeling and GIS could be combined in order to provide a more realistic pesticide exposure assessment.

So far, watershed exposure assessment in rice-cultivated areas has been limited to the development and application of representative scenarios at member-state level. The simulated watersheds, representing regionally common agronomic, pesticide and water management practices, were conceptualized using a combination of two models, rice water quality (RICEWQ) and river water quality (RIVWQ) (Miao et al., 2003; Warren et al., 2004; Karpouzas et al., 2006). However, using these watershed scenarios to calculate pesticide exposure ignores the inherent spatial variability in topography, land-use and soil properties existing within an agricultural watershed.

The aim of this study was to utilize spatial data in combination with mathematical modeling in order to estimate pesticide exposure in associated groundwater and surface-water systems of a rice-cultivated watershed.

\section{MATERIALS AND METHODS}

\subsection{Study area}

The region of Lombardy is located in the northern part of Italy (Fig. 1a). An important characteristic of this region is the presence of several large surface-water systems receiving water from agricultural land and discharging their water into the river Po, which constitutes the main surface-water body of the region (Fig. 1b). The climatic conditions can be described as temperate continental with an average temperature spatially ranging between 12.5 and $14{ }^{\circ} \mathrm{C}$. Total rainfall is about $900-1000 \mathrm{~mm}$ and is not uniformly distributed, with the higher rainfall occurring during spring with a second peak in autumn (Verro et al., 2002). 


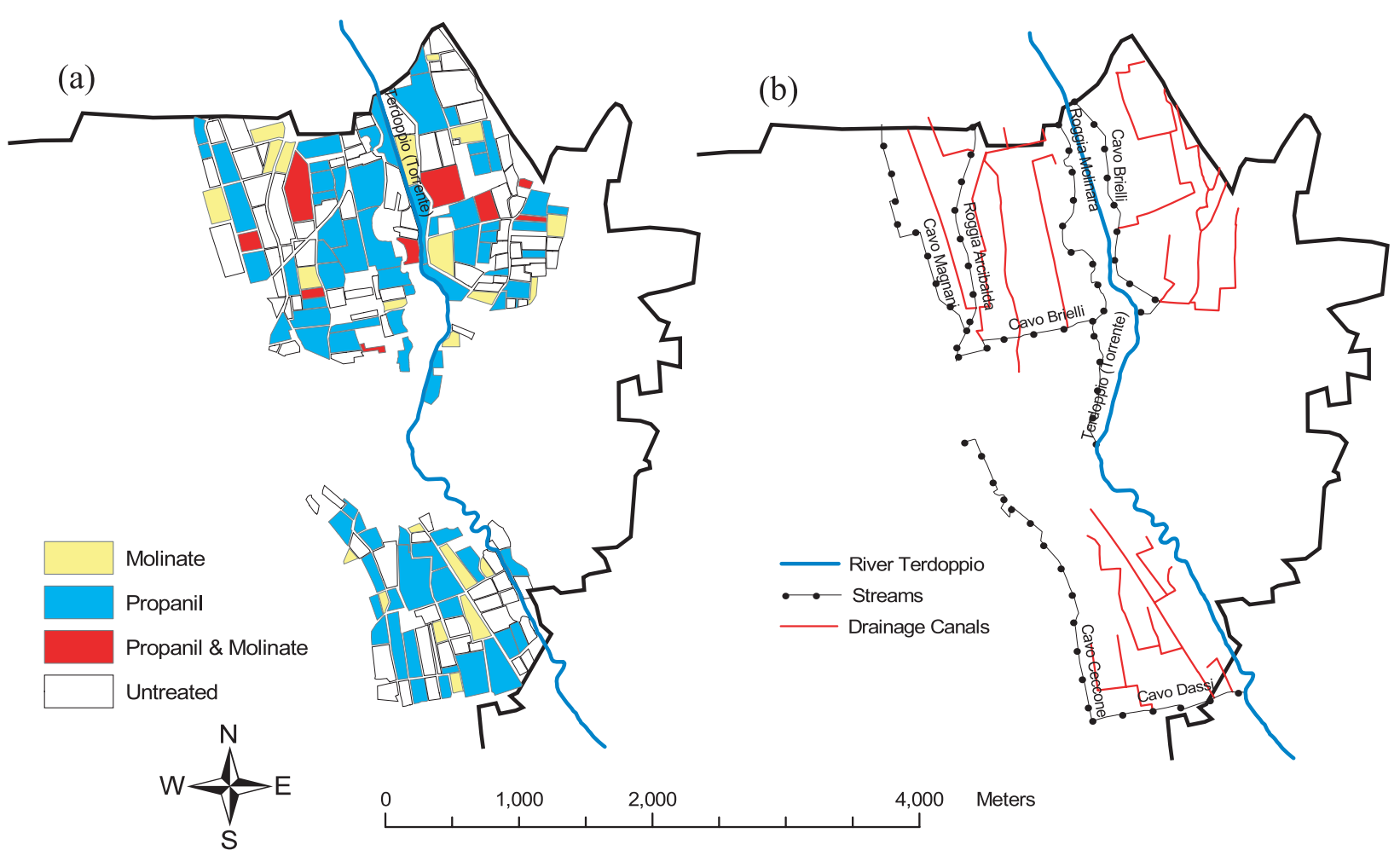

Figure 2. A representation of (a) the simulated rice-cultivated watershed comprising 201 paddies with varying pesticide application schemes and (b) the network of surface-water bodies of the watershed including drainage canals, streams and the river Terdoppio.

The southwestern part of the region of Lombardy (Fig. 1a), the province of Pavia, constitutes along with Vercelli (region of Piemonte, Torino) the main rice-cultivated zone in northern Italy (Fig. 1b). Along the northern part of the province of Pavia and in the center of the rice-cultivated area of the province is situated the community of Tromello, which is bypassed by the river Terdoppio (Fig. 1b). The community of Tromello has a total surface area of 3545.9 ha and ca. $61 \%$ of this is cultivated with rice. The river Terdoppio, which has a total length of $60 \mathrm{~km}$, bypasses the region of Lombardy before discharging its water into the river Po (Fig. 1b). A small self-contained ricecultivated watershed created around the segment of the river Terdoppio within the community of Tromello $(5.3 \mathrm{~km})$ was selected for assessing pesticide exposure in the river Terdoppio. The eastern part of the community of Tromello, where the watershed is situated, is characterized by permeable sandy, sandy loam soils compared with the western part of the community, where loams to loamy sands are the predominant types of soils (Fig. 1c). The selected rice-cultivated watershed comprised a total cultivated land of 467 ha, consisting of 201 rice paddies (Fig. 2a). A series of drainage canals, which receive outflow water and drift from rice paddies, streams which receive water from drainage canals and the river Terdoppio, constitute a network of surface-water bodies within this rice watershed (Fig. 2b).

\subsection{Landscape spatial analysis}

Spatial datasets on the scale of 1:50 000 for the province of Pavia, and most particularly for the community of Tromello, were provided by Ente Regionale per i Servizi all' Agricoltura e alle Foreste (ERSAF) Lombardy. These included detailed land-use, soil physicochemical properties, hydrology and surface-water topology and were all georeferenced to the GaussBoaga projection. Aerial images (maximum resolution 1:1000) of the studied area for the period 1998-1999 were also obtained by ERSAF and georeferenced to the Gauss-Boaga projection. Images and all spatial data were stored and processed in an ArcView GIS environment (Version 8.2, ESRI). Aerial images $(1: 1000)$ and land-use spatial data were overlaid in order to identify the rice-cultivated land of the community of Tromello which drains to the river Terdoppio, and digitize the relevant paddy-field polygons (Fig. 3). Soil data for each paddy field were obtained by overlaying field polygons onto soil datasets. If a field contained more than one soil type, simulation was done using the most dominant soil type in the field. Soil attributes, up to a depth of $2 \mathrm{~m}$, for each field included: soil texture (sand, clay and loam content), $\mathrm{pH}$, organic carbon content, cation exchange capacity, $\mathrm{CaCO}_{3}$ content and maximum waterholding capacity. Hydrological attributes included: soil layer permeability (indexed), soil inclination and the depth of the shallow groundwater aquifer.

The hydrography of the simulated watershed was only coarsely represented in the GIS dataset acquired by ERSAF. Thus, it included only first- and second-order rivers, and only some streams, but did not contain the smaller drainage canals which receive water and pesticide load from rice paddies and carry them on to streams and rivers. Therefore, drainage canals were digitized using aerial images and ground truthing, allowing 


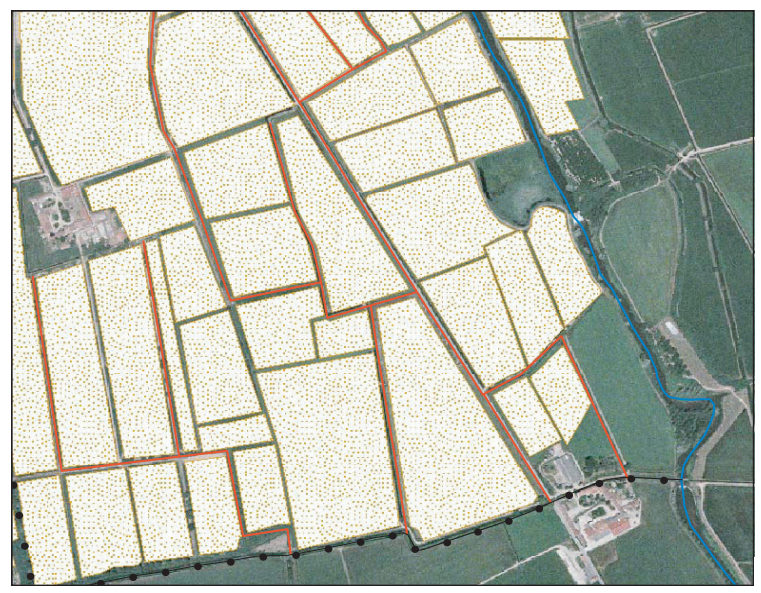

0 $290 \quad 580$ $1,160 \quad$ Meters 580
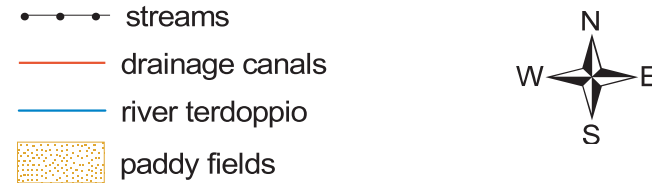

Figure 3. The aerial images of the simulated watershed (1:1000) overlaid by the digitized paddy fields and surface-water systems of the area.

a more realistic representation of the network of surface-water bodies of the area (Fig. 3). Drainage canals were interlinked with six streams (Cavo Brielli, C. Dassii, C. Ceccone, C. Magnani, Roggia Molinara and R. Arcibalda), which were all discharging their water within the simulated segment of the river Terdoppio (Fig. 2b). Therefore, the network of surface-water bodies of the watershed consisted of 21 drainage canals, six streams and the river Terdoppio (Fig. 2b). Further on-site scouting was employed to identify to which drainage canal each of the digitized paddies was draining.

\subsection{Model description}

RICEWQ 1.6.4v, using daily time steps, simultaneously tracks mass balance of the chemical in the rice foliage, the water column and the sediment. Unlike previous versions, RICEWQ $1.6 .4 \mathrm{v}$ allows irrigation and drainage to occur concurrently and also distinguishes the different degradation processes (hydrolysis, photolysis and microbial degradation) involved in the dissipation of pesticide in paddy water and sediment. The pesticide mass and water volume predicted to leach below paddy sediment are considered as inputs for the vadose zone transport submodel VADOFT, which subsequently calculates, at daily time steps, pesticide concentrations at the selected groundwater level. The top $5 \mathrm{~cm}$ of the soil profile is represented by the active sediment layer in RICEWQ and the remainder of the soil profile is represented as multiple compartments in VADOFT. The bottom of the active sediment layer is the interface between the two sub-systems represented by the two models. The model also provides daily summaries of the amount of pesticide and water lost from paddy systems due to runoff/overflow or controlled drainage. These losses can be used as water and pesticide mass input for the chemical transport model for riverine environments, RIVWQ 2.02.

RIVWQ 2.02. simulates the transport and fate of organic chemicals in riverine systems based on the theory of constituent mass balance. The system geometry is represented using a linkmode approach in which the water body is divided into a number of discrete junctions connected by flow channels. Dynamic constituent transport occurs between junctions via links and is a balance between river-driven flows and dispersion processes. Chemical transformation occurs within each node including dilution, volatilization, partitioning between water and sediment, decay in water and sediment and re-suspension from bed sediments. A detailed description of the models is given in the related users' manuals for RICEWQ $1.6 .2 \mathrm{~V}$ (Williams et al., 1999) and RIVWQ 2.02 (Williams et al., 2004) and also in previous works (Miao et al., 2003; Karpouzas et al., 2005).

\subsection{RICEWQ model parameterization}

A 12-year series of meteorological data (1990-2001) were obtained from the station of Castello D'Agogna which is located approximately $10 \mathrm{~km}$ northwest of the community of Tromello. The RICEWQ model requires daily precipitation $(\mathrm{cm})$ and evapotranspiration $(\mathrm{cm})$. In rice, evapotranspiration is assumed to be equal to pan evaporation, which is a valid assumption for an aquatic environment (Linsley and Franjini, 1979). Therefore, the potential evapotranspiration was calculated with the Penman-Monteith approach using the Global solar Radiation Estimate software RadEst 3.00 (Research Institute of Industrial Crops, Bologna, Italy) (Donatelli et al., 2003). This software uses daily precipitation, and daily maximum and minimum temperatures as minimum inputs in order to calculate the potential evapotranspiration (Donatelli et al., 2003).

A series of 10 different seeding dates during a 10-day period, from 20-30 April, were selected and were randomly assigned to each of the 201 simulated paddy fields. This period represents the main establishment period for rice crop in the Tromello basin. Subsequent agronomic (emergence, maturation and harvest), pesticide (application date) and water (application of irrigation or controlled drainage) management practices were varied accordingly (Tab. I). Personal interviews with local farmers and communication with local experts showed which rice-cropping system was used in which field. The majority of the paddies (149 paddies, 332 ha) were cultivated following the traditional cultivation method, with the remainder of the fields ( 52 paddies, $135 \mathrm{ha}$ ) cultivated with the dry-seed method. Water management and pesticide application practices in the paddies were varied according to the cultivation method applied in the field. Therefore, in paddies where the traditional mode of cultivation was used, irrigation commenced 15 days before seeding and rice was seeded directly onto paddies flooded with $10 \mathrm{~cm}$ of water. Crop emergence is usually complete 14 days after seeding (DAS). In contrast, in paddies where the dry-seed method was used, seeding of rice was done onto drained fields. Crop emergence is complete 20 DAS and coincides with the commencement of irrigation. Two additional drainage periods of $10 \mathrm{~d}$ were employed in all paddies 
Table I. Timing of the agronomic, water and pesticide management practices applied in rice paddies of the simulated watershed.

\begin{tabular}{|c|c|c|}
\hline Practices & Traditional & Dry - Seeded \\
\hline Seeding & \multicolumn{2}{|c|}{ 20-30 April } \\
\hline Emergence & 14 days after seeding & 20 days after seeding \\
\hline Irrigation commencement & 15 days before seeding & 20 days after seeding \\
\hline Application of molinate & 15 days after seeding & 25 days after seeding \\
\hline Application of propanil & 30 and 37 days after seeding & 40 and 47 days after seeding \\
\hline Drainage for fertilization & \multicolumn{2}{|c|}{ 1-10 July } \\
\hline Maturation & \multicolumn{2}{|c|}{5 September } \\
\hline Harvest & \multicolumn{2}{|c|}{15 September } \\
\hline
\end{tabular}

Table II. Values of parameters used by RICEWQ model.

\begin{tabular}{|c|c|c|c|}
\hline Parameters & \multicolumn{2}{|c|}{ Values } & Comments \\
\hline \multicolumn{4}{|l|}{ Agronomic Parameters } \\
\hline Maximum crop coverage at maturation & \multicolumn{2}{|c|}{0.90} & Conservative judgment \\
\hline Harvest flag & \multicolumn{2}{|c|}{-1} & Crop residues left in paddy after harvest \\
\hline Maximum drainage rate $(\mathrm{cm} / \mathrm{d})$ & \multicolumn{2}{|c|}{$1-8$} & Expert judgment \\
\hline Irrigation rate $(\mathrm{cm} / \mathrm{d})$ & \multicolumn{2}{|c|}{$1-4$} & Expert judgment \\
\hline Initial depth of paddy water (cm) & \multicolumn{2}{|c|}{0} & Depth of paddy water at the beginning of the simulation period \\
\hline Depth of paddy outlet (cm) & \multicolumn{2}{|c|}{$0 / 15$} & Expert judgment \\
\hline Pesticide Properties & molinate & propanil & \\
\hline Application rate $(\mathrm{kg} / \mathrm{ha})$ & 4.5 & 4.0 & Ferrero A., 2006 personal communication \\
\hline Degradation rate water / sediment $(1 / \mathrm{d})$ & 0.1034 & $0.354 / 0.499$ & US EPA $(2003 a, b)$ \\
\hline Organic carbon adsorption coefficient $(\mathrm{mL} / \mathrm{g})$ & 190 & 487.4 & US EPA $(2003 a, b)$ \\
\hline Water solubility (mg/L) & 880 & 225 & Tomlin (2000) \\
\hline Soil/Sediment Parameters & molinate & propanil & \\
\hline Depth of active sediment $(\mathrm{cm})$ & & & Med-Rice (2003) \\
\hline Bulk density $(\mathrm{g} / \mathrm{mL})$ & & & Calculated SoilPar 2.0, \\
\hline Organic carbon content $(\%)$ & & & GIS dataset \\
\hline Field capacity $\left(\mathrm{cm}^{3} / \mathrm{cm}^{3}\right)$ & & & Calculated SoilPar 2.0, \\
\hline Wilting point $\left(\mathrm{cm}^{3} / \mathrm{cm}^{3}\right)$ & & & Calculated SoilPar 2.0, \\
\hline Suspended sediment concentration $(\mathrm{mg} / \mathrm{L})$ & & & Miao et al. (2003) \\
\hline $\begin{array}{l}\text { Mixing depth for direct partitioning to } \\
\text { sediment (VBIND, } \mathrm{cm} \text { ) }\end{array}$ & & & Expert judgment \\
\hline Mixing velocity (VMIX, m/d) & 0.0 & 0.1 & Expert judgment \\
\hline
\end{tabular}

regardless of the method of cultivation: first at the beginning of July for fertilization and second at the time of crop maturation. A summary of the crop, water and pesticide practices utilized in both of the cultivation methods is shown in Table I.

RICEWQ $1.6 .4 \mathrm{v}$ could adequately simulate the flowthrough system of irrigation applied in the paddies of the simulated watershed. The drainage/irrigation routine of RICEWQ requires the dates of commencement and termination of irrigation or drainage, the depth of water maintained in the paddy field during irrigation/drainage periods, irrigation and drainage rates, and finally the depth of paddy outlet. Variation in the values of the latter parameter allows the user to select if an inter- mittent or continuous flow - through irrigation system will be simulated. Thus, setting the depth of paddy outlet to $0 \mathrm{~cm}$ and the paddy-water depth at which irrigation will commence and cease at 9.5 and $10.5 \mathrm{~cm}$, respectively, allowed irrigation and drainage to occur concurrently, while maintaining the water depth in the paddy field at ca. $10 \mathrm{~cm}$. In contrast, setting the depth of paddy outlet to $15 \mathrm{~cm}$ and the paddy-water depth at which irrigation will commence or cease at 5.5 to $9.5 \mathrm{~cm}$, respectively, will prevent controlled drainage of the paddy but maintain water depth at $10 \mathrm{~cm}$ by intermittent irrigation when needed. At each irrigation or drainage event, irrigation and drainage rates were varied accordingly (Tab. II). 
The pesticides included in the study were the rice herbicides propanil [3,4-dichloropropioanilide] and molinate [S-ethyl perhydroazepine-1-carbothioate]. Propanil and molinate are commonly applied in rice paddies of the area as late and early post-emergence applications, respectively, for the control of barnyardgrass (Echinochloa sp.) and other annual weeds. However, the most important reason for the inclusion of these herbicides as studied compounds was the availability of monitoring data for the river Terdoppio for these two herbicides, which allowed the validation of the simulated scheme. In the absence of regional pesticide-use data, personal interviews with local farmers were undertaken in order to establish a pesticide-use database for the paddies of the watershed. Paddies that were treated with neither of these two herbicides were considered as untreated but they were included in the simulation since they contributed water flow without pesticide in the receiving canals (Fig. 2a). Generally, 31 (73 ha) and 85 (243 ha) paddies of the watershed were treated with molinate and/or propanil, respectively. The remaining 85 paddies (150 ha) were treated with other herbicides and were considered as untreated.

Information regarding local pesticide application practices and application timing for the two herbicides were obtained from personal interviews and through personal communication with local experts (Ferrero A., 2006 personal communication). A single application per year was considered for molinate at the dose of $4.5 \mathrm{~kg} / \mathrm{ha}$ (Tab. II). Molinate is applied as granular application directly onto flooded paddies; thus, no drift inputs to adjacent canals were considered for molinate. After application of molinate, a paddy closure period of 7 days is employed. In contrast, a dual application of propanil per year is used in the Tromello area at a rate of $4 \mathrm{~kg} / \mathrm{ha}$ (Tab. II). A 7day interval between the first and the second application of propanil is commonly employed. Unlike molinate, propanil is sprayed onto drained paddies; thus, $2.77 \%$ of the application rate was considered as drift losses which were loaded onto neighboring drainage canals (FOCUS, 2001). Propanil-treated paddies are commonly re-flooded $48 \mathrm{~h}$ after application but no drainage is allowed in the flooded paddies for the next $48 \mathrm{~h}$. Molinate application was done 15 or 25 DAS in the paddies cultivated with the traditional or the dry-seeded method, respectively (Tab. I). The first and the second applications of propanil were done 30 and 37 DAS in paddies cultivated with the traditional method and 40 and 47 DAS in dry-seeded paddies (Tab. I).

Degradation rates of pesticides in paddy water and sediment, which are essential for the parameterization of RICEWQ, were derived from aerobic degradation studies in flooded soil or field dissipation studies in accordance with the Mediterranean Rice group's (Med-Rice) recommendations. Half-life field dissipation values derived from regulatory studies were used to calculate degradation rates of molinate and propanil in paddy water and sediment (US EPA, 2003a, b). The volatilization and photolysis routines of the RICEWQ model were disabled in order to avoid double accounting for these processes, since field dissipation values were used for model parameterization (Beulke and Brown, 2001). Adsorption coefficients, $\mathrm{K}_{\mathrm{d}}$, for each pesticide were estimated by their respective literature organic carbon adsorption coefficients, $\mathrm{K}_{\mathrm{oc}}$ (US EPA, 2003a, b).

Soil properties including $\mathrm{pH}$, organic carbon content, soil texture and cation exchange capacity for the surface soil layer of each field, derived from the GIS dataset, were utilized to calculate field capacity, wilting point and bulk density using Baumer pedo-transfer functions of the soil parameter estimate software (SOILPAR, Research Institute of Industrial Crops, Bologna, Italy) (Acutis and Donatelli, 2003). The initial soil moisture content $\left(\mathrm{cm}^{3} / \mathrm{cm}^{3}\right)$ was set to field capacity. The seepage rate in each field was obtained by the attribute permeability index of the GIS dataset. Values of 4, 3, 2 and 1 of the permeability index corresponded approximately to seepage rates of $0.2,0.4,0.6$ and $0.8 \mathrm{~cm} / \mathrm{d}$, respectively.

The soil horizon beneath each of the simulated paddy fields was divided into a varying number of texturally different soil layers according to the GIS spatial dataset. Measured values for saturated hydraulic conductivity, $K_{S}(\mathrm{~cm} / \mathrm{d})$, saturated $\left(\theta_{s}\right)$ and residual $\left(\theta_{r}\right)$ water content $\left(\mathrm{cm}^{3} / \mathrm{cm}^{3}\right)$ were available for certain fields in the southwestern part of the simulated watershed (Cascina Luigiana). Where no measured values were available, tabulated values obtained from the users' manual of the PRZM $3.0 \mathrm{v}$ for each soil layer according to soil texture were used for the parameterization of the VADOFT sub-model (Carsel et al., 1998). Retardation coefficients for each soil layer were calculated using the following formula

$$
R=1+\left(K_{d} \times B D / \theta_{s}\right)
$$

where $K_{d}\left(\mathrm{~cm}^{3} / \mathrm{g}\right)$ is the adsorption coefficient of the pesticide, $B D$ is the bulk density $\left(\mathrm{g} / \mathrm{cm}^{3}\right)$ and $\theta_{s}$ is the saturated water content $\left(\mathrm{cm}^{3} / \mathrm{cm}^{3}\right)$. A mean Darcy velocity, $q(\mathrm{~cm} / \mathrm{d})$, for the whole horizon of each field polygon was calculated following the formula

$$
q=K_{m} \frac{H_{i}}{\Sigma L_{i}}
$$

where $K_{m}(\mathrm{~cm} / \mathrm{d})$ is the mean saturated hydraulic conductivity, $H(\mathrm{~cm})$ is the hydraulic head and $L(\mathrm{~cm})$ is the length of each soil zone.

The first layer $(0-30 \mathrm{~cm})$ of the vadose zone, which is situated right beneath rice paddies, was considered as a water-saturated and anaerobic soil layer (Takagi et al., 1998; Fajardo et al., 2000). Therefore, degradation rates, which are essential for the parameterization of the VADOFT sub-model, were calculated by first-order half-life values obtained from anaerobic soil studies for molinate (Iwai and Kowatsura, 1982; EU, 2003) and propanil (US EPA, 2003a). First-order half-life values from aerobic soil studies with molinate (Iwai and Kowatsura, 1982; US EPA, 2003b; EU, 2003) and propanil (US EPA, 2003a) were utilized for calculating degradation rates in the remaining soil layers. In addition, a reduction in the degradation rate with depth was applied in accordance with Med-Rice recommendations (Med-Rice, 2003), and FOCUS groundwater scenarios (FOCUS, 2000). Therefore, the aerobic degradation rates of propanil and molinate were multiplied by biodegradation factors of $0.5,0.3$ and 0.1 for the second, third and fourth layers (>1 $\mathrm{m}$ depth) of the soil horizon, respectively. However, pesticide adsorption and thus the retardation coefficient for each soil layer was adjusted according to the measured organic carbon content of the separate soil horizons and no such default factors were used. A summary of the input parameters of the VADOFT sub-model is shown in Table III. 
Table III. Physicochemical and hydraulic parameters used in the VADOFT sub-model contained within RICEWQ.

\begin{tabular}{|c|c|}
\hline Parameters & Values \\
\hline Saturated hydraulic conductivity ${ }^{\mathrm{a}}\left(K_{S}\right)(\mathrm{cm} / \mathrm{d})$ & Tabulated values by Carsel et al. (1998) \\
\hline Saturated water content ${ }^{\mathrm{a}}\left(\theta_{s}\right)\left(\mathrm{cm}^{3} / \mathrm{cm}^{3}\right)$ & Tabulated values by Carsel et al. (1998) \\
\hline Residual water content ${ }^{\mathrm{a}}\left(\theta_{r}\right)\left(\mathrm{cm}^{3} / \mathrm{cm}^{3}\right)$ & Tabulated values by Carsel et al. (1998) \\
\hline Effective porosity $(\varphi)$ (dimensionless) & $\varphi=\theta_{s}-\theta_{r}$ \\
\hline Residual water-phase saturation $\left(S_{w r}\right)$ (dimensionless) & $S_{w r}=\theta_{r} / \theta_{s}$ \\
\hline Leading coefficient of saturation versus capillary head $(\alpha)(1 / \mathrm{cm})$ & Tabulated values by Carsel et al. (1998) \\
\hline Power index of saturation versus capillary head relationship $(\beta)(1 / \mathrm{cm})$ & Tabulated values by Carsel et al. (1998) \\
\hline Power index of saturation versus capillary head relationship $(\gamma)(1 / \mathrm{cm})$ & Tabulated values by Carsel et al. (1998) \\
\hline Longitudinal dispersion $\left(\alpha_{L}\right)(\mathrm{cm})^{\mathrm{b}}$ & $\alpha_{L}=0.1 x_{v}$ \\
\hline Retardation coefficient $(R)$ (dimensionless) & Equation (1) \\
\hline Darcy velocity $(q)(\mathrm{cm} / \mathrm{d})$ & Equation (2) \\
\hline Degradation rates $(1 / d) \quad 1$ st horizon & $0.231^{\mathrm{c}} / 0.0068^{\mathrm{d}}$ \\
\hline 2nd horizon & $0.4678 / 0.0121$ \\
\hline 3rd horizon & $0.281 / 0.00723$ \\
\hline 4th horizon (>1 m depth) & $0.0936 / 0.00241$ \\
\hline
\end{tabular}

${ }^{\mathrm{a}}$ Measured values for these parameters were available for a number of fields.

${ }^{\mathrm{b}}$ Longitudinal dispersion was calculated by the respective equation where $x_{v}$ is the length of the soil horizon considered each time.

${ }^{c}$ Degradation rates for propanil.

d Degradation rates for molinate.

\subsection{RIVWQ model parameterization}

Hydrological and other characteristics of the simulated surface-water systems are listed in Table IV. Dimensions of the simulated surface-water bodies, water-flow velocity $(\mathrm{m} / \mathrm{s})$, discharge $\left(\mathrm{m}^{3} / \mathrm{s}\right)$, flow direction and shape of cross-section were all derived from on-site observations. Drainage canals had a rectangular shaped cross-section with top width and depth of $1.5 \mathrm{~m}$, and flow velocity of $0.01 \mathrm{~m} / \mathrm{s}$. The six streams had in most of their simulated length a rectangular cross-section with a top width of $6 \mathrm{~m}$, depth of $2 \mathrm{~m}$ and a flow velocity of $0.07 \mathrm{~m} / \mathrm{s}$. The segment of the river Terdoppio bypassing the community of Tromello had a rectangular cross-section, top width $15 \mathrm{~m}$, depth of $2 \mathrm{~m}$ and flow velocity of $0.2 \mathrm{~m} / \mathrm{s}$. The muskingum routine of the RIVWQ model was disabled since it is considered relevant only for large dynamic surface-water systems (Williams et al., 2004).

Degradation rates of pesticides in water and sediment of the surface-water bodies were derived from appropriate aerobic water/sediment studies (US EPA, 2003a; EU, 2003). Adsorption of molinate and propanil onto river sediment was calculated from their respective $\mathrm{K}_{\mathrm{oc}}$ values for organic carbon content of $0.9 \%$ for the river sediment (Med-Rice, 2003).

For modeling purposes, all simulated water bodies were divided into several segments of varying lengths. The total length of the simulated drainage canals varied from 600 to $2000 \mathrm{~m}$, and they were divided into segments of different lengths (100 to $540 \mathrm{~m}$ ). Pesticide load via drift (when considered) and/or controlled drainage from paddies onto their corresponding drainage canals were occurring at certain nodal points along the length of the receiving canal corresponding to the beginning of a modeling segment. The length of the sim- ulated streams varied from $1200 \mathrm{~m}$ for C. Brielli to nearly $3000 \mathrm{~m}$ for R. Molinara. Streams were also divided into segments of lengths varying from 100 to $700 \mathrm{~m}$. The simulated part of the river Terdoppio was divided into segments of lengths varying from 250 to $1000 \mathrm{~m}$. The streams C. Brielli, R. Molinara and C. Dassi, which were carrying pesticide and water load from drainage canals and the other streams of the watershed, were crossing river Terdoppio at points 1800,2900 and $5160 \mathrm{~m}$ along the length of its simulated segment, respectively (Fig. 2b).

\subsection{General modeling scheme}

A combination of the models RICEWQ and RIVWQ was used to conceptualize the simulated watershed. Previous studies using the combination of these models successfully simulated the fate of herbicides in surface-water bodies associated with rice-paddy areas (Miao et al., 2003; Warren et al., 2004). The fate of propanil and molinate in the selected paddies of the watershed was simulated using RICEWQ. Simulations were also performed for the untreated paddies. The RICEWQ simulations produced predicted concentrations for the two pesticides at a depth of $2 \mathrm{~m}$, which was the depth of the shallow groundwater aquifer in the vast majority of the paddies. The annual average PEC for the year 1999, which was the reference year for the spatial data, was used for assessing the risk of groundwater contamination by the two herbicides. In addition, RICEWQ simulations produced pesticide mass and paddy water loadings as daily outflow from paddies. These loadings were used as pesticide mass and water inputs for the receiving drainage canals and streams. In addition, $2.77 \%$ of the application rate of propanil was loaded as drift onto drainage canals adjacent to propanil-treated paddies. The pesticide mass 
Table IV. Values of parameters used by the RIVWQ model.

\begin{tabular}{|c|c|c|}
\hline Parameters & Values & Comments \\
\hline \multicolumn{3}{|l|}{ Sediment Parameters } \\
\hline Settling velocity $(\mathrm{m} / \mathrm{d})$ & 2.0 & Expert judgment \\
\hline Mixing velocity (m/d) & 0.1 & $"$ \\
\hline Mixing depth for direct partitioning to bed sediment $(\mathrm{cm})$ & 0.1 & $"$ \\
\hline Depth of active sediment $(\mathrm{cm})$ & 5 & Med-Rice (2003) \\
\hline Porosity (dimensionless) & 0.43 & Calculated from bulk density (Miao et al., 2003) \\
\hline Bulk density (g/mL) & 1.5 & Med-Rice (2003) \\
\hline Concentration suspended sediment $(\mathrm{m} / \mathrm{d})$ & 45 & Expert judgment \\
\hline \multicolumn{3}{|l|}{ Canal Parameters } \\
\hline Qc coefficient in stage-flow rating curve & 13.64 & Williams et al. (2004) \\
\hline Qd coefficient in stage-flow rating curve & 0.6 & $"$ \\
\hline Dispersion coefficient $\left(\mathrm{m}^{2} / \mathrm{s}\right)$ & 0.01 & $"$ \\
\hline Base flow $\left(\mathrm{m}^{3} / \mathrm{s} / \mathrm{km}^{2}\right.$ of drainage area) & 0.0 & $"$ \\
\hline Dead storage (m depth) & 0.10 & $"$ \\
\hline \multicolumn{3}{|l|}{ Stream Parameters } \\
\hline Qc coefficient in stage-flow rating curve & 2.44 & Williams et al. (2004) \\
\hline Qd coefficient in stage-flow rating curve & 0.60 & $"$ \\
\hline Dispersion coefficient $\left(\mathrm{m}^{2} / \mathrm{s}\right)$ & 1.0 & $"$ \\
\hline Base flow $\left(\mathrm{m}^{3} / \mathrm{s} / \mathrm{km}^{2}\right.$ of drainage area) & $0.57-6.9$ & $"$ \\
\hline Dead storage (m depth) & 0.0 & Not relevant for large surface-water bodies \\
\hline \multicolumn{3}{|l|}{ River Parameters } \\
\hline Qc coefficient in stage-flow rating curve & 0.90 & Williams et al. (2004) \\
\hline Qd coefficient in stage-flow rating curve & 0.60 & $"$ \\
\hline Dispersion coefficient $\left(\mathrm{m}^{2} / \mathrm{s}\right)$ & 2.0 & , \\
\hline Base flow $\left(\mathrm{m}^{3} / \mathrm{s} / \mathrm{km}^{2}\right.$ of drainage area) & 2.6 & 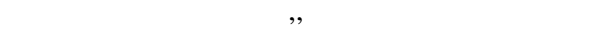 \\
\hline Dead storage (m depth) & 0.0 & Not relevant for large surface-water bodies \\
\hline
\end{tabular}

corresponding to the $2.77 \%$ of the application rate of propanil was manually incorporated at the day of application into the output file of RICEWQ, which provides daily summaries of pesticide mass and water losses via overflow or controlled drainage. These files were utilized in order to create pesticide mass and water flow input files for the RIVWQ model.

The fate of herbicides in the network of drainage canals, streams and the river Terdoppio was simulated by RIVWQ. Predicted concentrations of the two herbicides at the most downstream point of the simulated segment of the river Terdoppio, downstream of the community of Tromello, were compared with measured concentrations of propanil and molinate obtained from a sampling point close to the point selected for the year 1999 (Fig. 1d). Monitoring data were provided by the analytical laboratory of the Province of Pavia which performs regular monitoring studies in the primary surface-water bodies of the province. Water samples were collected from three points along the route of the river Terdoppio in the Region of Lombardy. These three points were at Vigevano, Alagna and Zinasco. Vigevano is located north of the community of Tromello, unlike Zinasco which is situated south of the community of Tromello near the crossing point of the river Terdoppio with the river Po. Alagna is situated downstream of the community of Tromello (Fig. 1d), and the measured concentrations of the herbicides at this point of the river Terdoppio were considered as the most appropriate to be compared with the predicted concentrations of the two herbicides in the river. Triplicate samples were collected at monthly intervals (12 sampling dates) from each of the above sampling points. Samples were transferred to the laboratory and analyzed for the presence of various pesticides including chloroacetamides (alachlor and metolachlor), triazines (atrazine, simazine and terbuthylazine), trifluralin, bentazone, propanil, molinate and organochlorines (DDT, aldrin and dieldrin).

\section{RESULTS AND DISCUSSION}

\subsection{Groundwater risk assessment}

Groundwater predicted environmental concentrations calculated at the 2-m depth for the year 1999 did not exceed the trigger value of $0.1 \mu \mathrm{g} / \mathrm{L}$ in any of the 85 propanil - treated paddies of the watershed. In addition, predicted environmental concentrations of propanil for the same year were constantly well below $0.1 \mu \mathrm{g} / \mathrm{L}$ even at the $1-\mathrm{m}$ depth, which is considered 


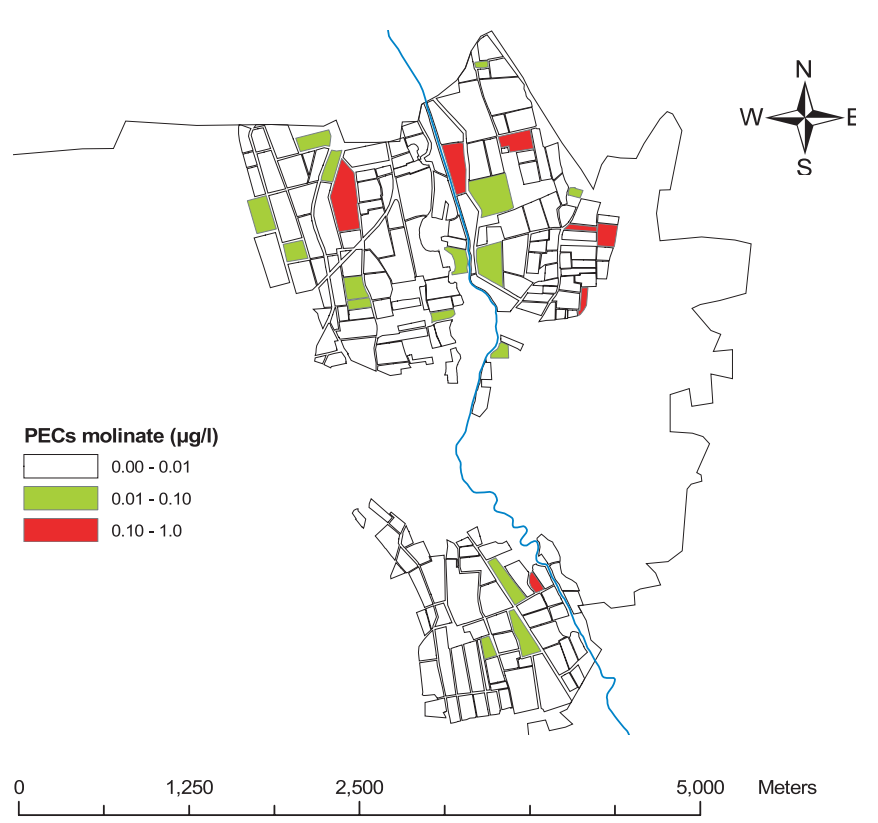

Figure 4. A spatial representation of the groundwater predicted environmental concentrations (PECs) $(\mu \mathrm{g} / \mathrm{L})$ of molinate as predicted by the RICEWQ model for the year 1999 at the 2-m depth beneath the simulated paddy fields.

as the relevant depth for regulatory groundwater risk assessment (FOCUS, 2000). These results suggest a low risk for groundwater contamination of the area by the use of propanil. This is in agreement with previous groundwater monitoring studies in other rice-cultivated areas. Validated monitoring studies from groundwater aquifers performed by the United States Geological Survey in a representative rice-cultivated area in the USA (California, Arkansas, Missouri and Mississippi) showed that propanil was only detected twice out of a total of 124 samples, all collected from rice-cultivated zones. Furthermore, the concentrations of propanil in the positive samples never exceeded the detection limit of $0.05 \mu \mathrm{g} / \mathrm{L}$ (US EPA, 2003a). Subsequent monitoring studies by the United States Geological Survey employed in shallow groundwater aquifers showed that propanil was not frequently detected in the water samples and its maximum concentration was $0.008 \mu \mathrm{g} / \mathrm{L}$ (US EPA, 2003a). Propanil is a high-input herbicide which is commonly applied in rice fields in Europe. However, its relatively high dissipation rate in water and sediment limits its movement to deeper layers of the soil horizon beneath ricepaddy fields (Santos et al., 1998).

In contrast to propanil, groundwater predicted environmental concentrations of molinate exceeded the trigger value of $0.1 \mu \mathrm{g} / \mathrm{L}$ in 7 of the 31 paddy fields of the watershed which were treated with molinate (Fig. 4). In addition, groundwater predicted environmental concentrations of molinate at the 2-m depth varied between 0.01 and $0.1 \mu \mathrm{g} / \mathrm{L}$ in another 16 of the 31 molinate-treated paddies of the watershed (Fig. 4). Our results suggest that molinate poses some risk for groundwater contamination in certain areas of the watershed which are characterized by high soil permeability. Our findings are consistent with previous findings by Riparbelli et al. (1996) who reported the fre-

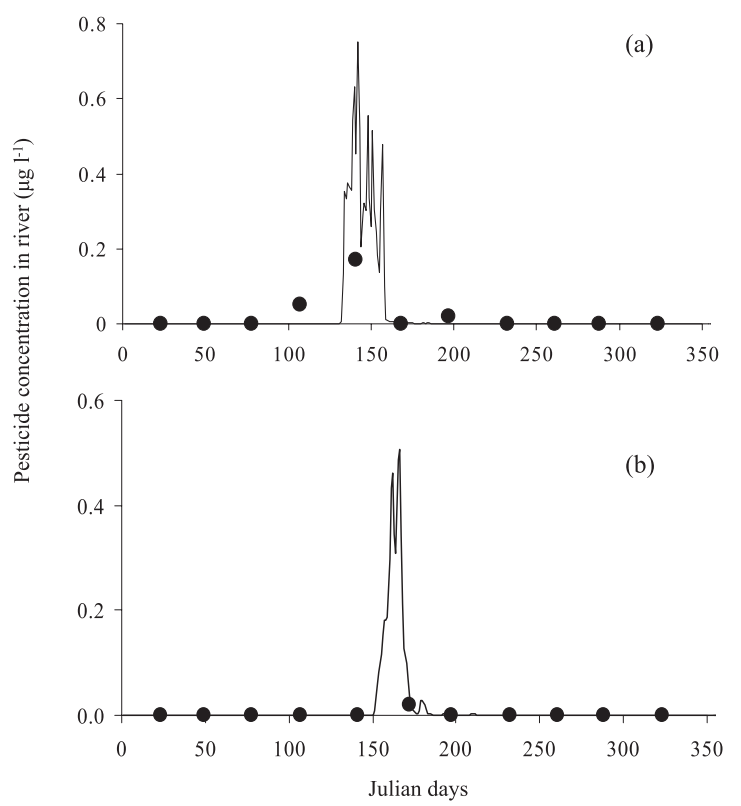

Figure 5. Simulated $(-)$ and measured $(\bullet)$ concentrations of molinate (a) and propanil (b) in the most downstream point of the simulated segment of the river Terdoppio.

quent detection of molinate at concentrations exceeding $0.1 \mu \mathrm{g} / \mathrm{L}$ in groundwater aquifers in Lombardy. Similar results were obtained from a monitoring study employed in the main ricecultivated area of Greece, the Axios river basin, where molinate was frequently detected in the shallow phreatic horizon at concentrations exceeding $0.1 \mu \mathrm{g} / \mathrm{L}$ (Papadopoulou-Mourkidou et al., 2004). Similarly, in validated monitoring studies from groundwater aquifers performed by the United States Geological Survey in a representative rice-cultivated area in the USA (California, Arkansas, Missouri and Mississippi) molinate was detected at concentrations ranging from $0.005-1.5 \mu \mathrm{g} / \mathrm{L}$ with most of the detections being at concentrations lower than $0.056 \mu \mathrm{g} / \mathrm{L}$ (US EPA, 2003b). This is in agreement with our simulations for molinate, where predicted environmental concentrations at the groundwater aquifers in the majority of the molinate-treated paddies ranged from $0.01-0.1 \mu \mathrm{g} / \mathrm{L}$.

\subsection{Pesticide risk assessment in the river Terdoppio}

Concentrations of propanil in the simulated drainage canals and river were markedly lower than the corresponding concentrations of molinate (Fig. 5). This could be attributed to the rapid dissipation of propanil in rice-paddy systems (Santos et al., 1998; US EPA., 2003a), compared with the respectively slower dissipation of molinate (Ross and Sava, 1986). The temporal distribution of the predicted concentrations of the two herbicides in the most downstream point of the simulated segment of the river Terdoppio with measured values obtained from approximately the same sampling point of the river are shown in Figure 5. Comparison of the predicted concentrations of molinate for the year 1999 with measured values indicates an acceptable agreement, although the modeling scheme used slightly over-predicted the peak concentration of molinate (Fig. 5a). Although an attempt was made to minimize as much 
as possible the uncertainties associated with input variables, the absence of certain information including pesticide-use data (pesticide application rate and application time), exact timing of agronomic practices (seeding and emergence), use of pedotransfer functions to calculate the bulk density and wilting point of paddy soil and the use of literature degradation and adsorption values might have introduced some uncertainties into the predictions of the RICEWQ model. Previous uncertainty analysis by Miao et al. (2004) showed that some of the above parameters including pesticide application rate and timing and pesticide adsorption coefficient are major contributors to uncertainty in the prediction of pesticide concentrations in runoff/overflow water. These uncertainties might have been responsible for the discrepancy between observed and measured concentrations of molinate in the river Terdoppio.

The highest measured concentration of molinate in the river Terdoppio was detected at the same period of time as the highest predicted concentration of molinate in the river. This suggests that the modeling scheme applied in this study realistically predicted the temporal distribution of molinate residues in the water of the river Terdoppio. Similarly, comparison of measured with predicted concentrations of propanil in the river Terdoppio indicated a good agreement although the measured concentrations of propanil exceeded the limit of detection only once in 1999 (Fig. 5b). Infrequent collection of samples from the river Terdoppio might have missed the peak of the propanil concentration in the riverine water.

\section{CONCLUSION}

So far, pesticide risk assessment in rice paddies in Europe has concentrated on the development of lower tier tools and techniques such the Med-Rice guidelines (Med-Rice, 2003), and the novel tier 2 model SWAGW (Cervelli et al., 2004), thus overlooking the need for higher tier analysis. Recent advances in higher tier exposure assessment in rice-paddy areas, including the validation of the RICEWQ model for European application (tier 3) and the combined use of RICEWQ with the surface-water model RIVWQ (tier 4) allowed the description of the rice environment in a more realistic way (Warren et al., 2004; Karpouzas et al., 2006). This study represents another step towards the development of refined, realistic modeling of the rice environment at the watershed level. Our results suggest that landscape analysis of pesticide exposure in rice-cultivated watersheds using GIS tools in combination with mathematical modeling could provide a realistic prediction of exposure on a spatial scale. Availability of detailed information regarding pesticide use, pesticide application and timing for each farm within an agricultural watershed would significantly improve prediction accuracy at the watershed level. This study offers preliminary evidence that landscape risk assessment can be an acceptable method for refining risk in rice-paddy areas.

Acknowledgements: This paper was produced within the framework of a Marie Curie individual fellowship "Environmental risk analysis leading to simulating a sustainable ecosystem management in rice areas" held by Dr. D. Karpouzas (QLK5-CT-2002-51598). The authors are grateful to Sig. Broglia, Province of Pavia, for providing the monitoring data.

\section{REFERENCES}

Acutis M., Donatelli M. (2003) Soilpar 2.00: Software to estimate soil hydrological parameters and functions, Eur. J. Agron. 18, 373-377.

Beulke S., Brown C.D. (2001) Evaluation of methods to derive pesticide degradation parameters for regulatory modeling, Biol. Fert. Soils 33, 558-564.

Capri E., Cavanna S. (1999) Ground and surface water bodies contamination by pesticide use in paddy field, in: Capri E., Cervelli S., Arnold G. (Eds.), Environmental risk parameters for use of plant protection products in rice, Tipolitographia Press, Piacenza, Italy, pp. $48-71$.

Carsel R.F., Imhoff J.C., Hummel P.R., Cheplick J.M., Donigian A.S. Jr. (1998) PRZM - 3, a Model for predicting Pesticide and Nitrogen Fate in the Crop Root and unsaturated soil zones: Users Manual for release 3.0. National Exposure Research Laboratory, Office of Research and Development, U.S. Environmental Protection Agency, Athens, GA, USA.

Cervelli S., Cervelli F., Cervelli L. (2004) A Step 2 approach to compute water, soil and sediment PECs and TWAs for the inclusion of rice pesticides in Annex I of the EU Council Directive 91/414/EEC, in: Ferrero A., Vidotto F. (Eds.), Proceedings of the Conference challenges and opportunities for sustainable rice-based production systems, Edizioni Mercuri, Torino, Italy, pp. 431-443.

Cryer S.A., Fouch M.A., Peacock A.L., Havens P.L. (2006) Characterizing agrochemical patterns and effective BMPs for surface waters using mechanistic modeling and GIS, Environ. Model. Assess. 6, 195-208.

Donatelli M., Bellocchi G., Fontana F. (2003) RadEst 3.00: Software to estimate daily radiation data from commonly available meteorological variables, Eur. J. Agron. 18, 363-367.

EU (2003) Review report for the active substance molinate; Health and Consumer Protection Directorate-General. European Commission Document Reference SANCO/3047/99, Brussels, Belgium, 38 p.

Fajardo F.F., Takagi K., Usui K. (2000) Dissipation of mefenacet and pretilachlor in paddy soils under laboratory oxidative and reductive conditions, J. Weed Sci. Tech. 45, 250-253.

FOCUS (2000) Groundwater scenarios in the EU plant protection product review process. Report of the FOCUS Groundwater Scenarios Workgroup, European Commission Document Reference Sanco 321, Brussels, Belgium, p. 147.

FOCUS (2001) Surface water scenarios in the EU evaluation process under 91/414/EEC, Report of the FOCUS Working Group on surface water scenarios, European Commission Document Reference SANCO/4802/2001, Brussels, Belgium, p. 245.

FOCUS (2006) Report of the FOCUS Working Group on Landscape and Mitigation Factors in Ecological Risk Assessment, EC Document, 2006 (in press).

Iwai Y., Kowatsuka S. (1982) Degradation of the herbicide molinate in soils, Pest. Sci. 7, 487-497.

Karpouzas D.G., Ferrero A., Vidotto F., Capri E. (2005) Application of the RICEWQ-VADOFT model for simulating the environmental fate of pretilachlor in rice paddies, Environ. Toxicol. Chem. 24, $1007-1017$

Karpouzas D.G., Capri E., Papadopoulou-Mourkidou E. (2006) Basinscale risk assessment in rice paddies: An example based on the Axios river basin in Greece, Vadose Zone J. 5, 273-282.

Kay S.A. (1998) Use of GIS and Remote Sensing in agrochemical regulatory strategies, CSI Visions, p. 1.

Lake I., Lovett A.A., Hiscock K.M., Betson M., Foley A., Sunnenberg G., Evers S., Fletcher S. (2003) Evaluating factors influencing groundwater vulnerability to nitrate production: developing the potential of GIS, J. Environ. Manage. 68, 315-328.

Linsley P.K., Franjini J.B. (1979) Water-resources engineering, 3rd ed., McGraw-Hill, New York, USA.

Med-Rice. (2003) Final report of the working group MED-RICE prepared for the European Commission in the framework of Council Directive 
91/414/EEC, European Commission Document Reference Sanco 1092, Brussels, Belgium.

Miao Z., Padovani L., Riparbelli C., Ritter A.M., Trevisan M., Capri E. (2003) Prediction of the environmental concentration of pesticide in paddy field and surrounding surface water bodies, Paddy Water Environ. 1, 121-132.

Miao Z., Trevisan M., Capri E., Padovani L., Del Re A.A.M. (2004) Uncertainty assessment of the model RICEWQ in northern Italy, J. Environ. Qual. 33, 2217-2228.

Padovani L., Capri E., Trevisan M. (2004) Landscape-level approach to assess aquatic exposure via spray drift for pesticides: a case study in a Mediterranean area, Environ. Sci. Technol. 38, 3239-3246.

Padovani L., Capri E., Padovani C., Puglisi E., Trevisan M. (2006) Monitoring tricyclazole residues in rice paddy watersheds, Chemosphere 62, 303-314.

Papadopoulou-Mourkidou E., Karpouzas D.G., Patsias J., Kotopoulou A., Milothridou A., Kintzikoglou K., Vlachou P. (2004) The potential of pesticides to contaminate the groundwater resources of the Axios river basin. Part II. Monitoring study in the south part of the basin, Sci. Total Environ. 321, 147-164.

Riparbelli C., Scalvini C., Bersani M., Auteri D., Azimonti G., Maroni M. (1996) Groundwater contamination from herbicides in the region of Lombardy - Italy, period 1986-1993, in: Del Re A.A.M., Capri E., Evans S.P., Trevisan M. (Eds.), Proceedings of the X Symposium Pesticide Chemistry, The environmental fate of xenobiotics, La Goliardica Pavese, Piacenza, Italy, pp. 559-566.

Ross L.J., Sava R.J. (1986) Fate of thiobencarb and molinate in rice fields, J. Environ. Qual. 15, 220-225.

Santos T.C.R., Rocha J.C., Alonso R.M., Martinez E., Ibanez C., Barcelo D. (1998) Rapid degradation of propanil in rice crop fields, Environ. Sci. Technol. 32, 3479-3484.
Takagi K., Fajardo F.F., Inao K., Kitamura Y. (1998) Predicting pesticide behavior in a lowland environment using computer simulation, Rev. Toxicol. 2, 269-286.

Tomlin C. (2000) The Pesticide Manual, 11th ed., British Crop Protection Council, The Royal Society of Chemistry, Farnham, UK.

US EPA (2003a) Re-registation eligibility decision for propanil (N-(3,4dichlorphenyl)-propanamide), Unites States of America Environmental Protection Agency, Office of pesticide programs, Special review and re-registration decision.

US EPA (2003b) Appendix D, Environmental fate assessment and guideline summaries: Molinate, Unites States of America Environmental Protection Agency, Office of pesticide programs.

Verro R., Calliera M., Maffioli G., Auteri D., Sala S., Finizio A., Vighi M. (2002) GIS-Based system of surface water risk assessment of agricultural chemicals. 1. Methodological approach, Environ. Sci. Technol. 36, 1532-1538.

Warren R.L., Ritter A.M., Williams W.M. (2004) A rice herbicide Tier 2 exposure assessment for European rivers based on RICEWQ/ RIVWQ, in: Ferrero A., Vidotto F. (Eds.), Proceedings of the Conference challenges and opportunities for sustainable rice-based production systems, Edizioni Mercuri, Torino, Italy, pp. 523-533.

Williams W.M., Ritter A.M., Cheplick J.M., Zdinak C.E. (1999) RICEWQ: Pesticide runoff model for rice crops - user's manual and program documents version 1.6.1. Waterborne Environment Inc., S.E. Leesburg, VA, USA.

Williams W.M., Zdinak C.E., Ritter A.M., Cheplick J.M., Singh P. (2004) RIVWQ: Chemical transport model for riverine environments user's manual and program documentation version 2.02. Waterborne Environment Inc., S.E. Leesburg, VA, USA. 